\title{
Definition and Identification of Key Talent in Enterprises
}

\author{
Jianzhong Li \\ School of Economics and Management \\ Baotou Teachers College \\ Baotou, China \\ E-mail:1jzhrm@163.com
}

\begin{abstract}
Key Talents with high quality and high performance plays a vital role for the realization of the 0enterprise's strategy. This paper discusses the significance of Key Talent for enterprise to realize strategic target and compares the definitions of Key Talent of some domestic and foreign scholars. Based on experts' and scholars' research, the definition of enterprise Key Talent is put forward, and then the characteristics that Key Talent should possess in the process of enterprise development and the purpose of carrying on Key Talent recognition are analyzed. This paper focuses on the process of using two dimensions, post evaluation and competency analysis, to identify Key Talent, which innovate the identification method of core talent and provides the theoretical basis and practical guidance for enterprise to indentify Key Talent.
\end{abstract} target

Keywords-competence, key talent, post evaluation, strategic

\section{INTRODUCTION}

The competition of enterprises comes down to the competition of talents. Therefore, the human resource strength of an enterprise reflects the strength of the enterprise from another side. Along with the changes of external environ ment and the transformation of organizational inside, how to respond to challenges through the effective management of human resources and realize the long-term development have become two important problems for an enterprise. To master core technology, control key resources and possess Key Talents with high quality and high performance plays a vital role for the realization of the enterprise's strategy. Professor Snell of American Cornel University puts forward the model of "Strategy-Core Competence-Key Talent", which means that a company should possess corresponding organizational core competence it expects to win competitive edge, and then which kind of Key Talent is needed can be deduced [1]. It also shows that the Key Talent has important significance for the promotion of enterprise's competitiveness, therefore, which employees are Key Talents and how to effectively and accurately identify Key Talent are problems that top management and human resource management need to solve. This paper puts forward that analyzing and identifying Key Talent according to post evaluation and competence applying the theory of Human Resource Management Development.

\section{DEFINITION OF KEY TALENT}

\section{A. Key talent}

Professor Snell of American Cornel University divides the organizational human resource into four types according to the standards of human-resource value and scarcity, which are "Key Talent, General Talent, Subsidiary Talent and Unique Talent" [2]. Based on Snell Model, Profess or Peng Jianfeng considers that the human resource of an enterprise can be divided into Key Talent, Scarce talent, Subsidiary Talent and General Talent starting from two dimensions of scarcity and strategic value. He regards that Key Talents, who are talent with high strategic-value and scarcity of the market, are the fundamental source of enterprise competiveness and core competence [3].

The definition of Key Talent has not been formed into a unified view in academic circles. Leigh Branham defined the key staff from the irreplaceable point of view, and considered that key staff is the most important, the most difficult to find, the most indispensable and irreplaceable key figures who can ensure the success of management strategy [4].

Gregury G. Dess and Jason D. Shaw studied Key Talent from the perspective of social organizational network system and thought that Key Talent is the talent who possesses the influential ability to create multiple affiliated values in the organizational network [5].

Zhang Chengfen pus forward that Key Talent in a high and new tech enterprise includes core operating personnel, core technicist (mastering the core technology of the enterprise), core management personnel and key marketing personnel (grasping the important channel or customer resources). These Key Talent master key intangible resources, possess abundant technical experience in the industry, master plentiful customer resources and own significant relationship resources for management, all of which construct the unduplicated core competitiveness of the high and new tech enterprise [6].

It can be found through the summarization of scholars' and practitioners' views that, the requirement of post competency and self able quality for Key Talent is very high. Therefore, this paper puts forward the definition of Key Talent which is the talents occupy key positions, possess high performance 
ability, play an important role in the realization of enterprise's strategic objectives.

\section{B. Characteristics of key talent}

\section{1) High post value.}

China's traditional Human Resource Management (HRM) mode is based on post, so position analysis and post evaluation is an important work for HRM through which key posts that play a key role on enterprise development can be determined. Key Talent often occupies the key posts of an enterprise. These posts, scarce in enterprise management or grade level, whose works play a decisive role on the realization of the strategic target and highly correlate to enterprise strategy, so the post value of Key Talent is high.

\section{2) High able quality.}

Matching between people and posts is the theme of HRM, so talents who can be competent to the key positions are Key Talent. Knowledge, ability, skills, experience and deep personality characteristics that human resources possess are vital to realize individual and corporate performance. These talents who can make unique contribution affect the survival and development of the enterprise. Therefore, Key Talent should possess high quality and ability.

\section{3) High performance standard.}

The realization of enterprise strategic target ultimately depends on the completion of individual performance target. Key Talent grasps core business of the enterprise and controls key resources of the enterprise, so the performance of Key Talent has an immediate impact of enterprise's success or failure.

\section{CONNOT ATION AND PURPOSE OF IDENTIFYING KEY} TALENT

The identification of Key Talent is to use of scientific means and methods to analyze relevant information of posts and talent and find out talents who play a key role on realizing enterprise strategic target. How to identify Key Talent is of signality to an enterprise, whose main purposes are as follows.

\section{1) Strategic purpose.}

The identification of Key Talent is in favor of realizing strategic target. Activities of Key Talent are often connected with strategic objective because of the particularity of Key Talent which means that the correlation between the contributions of Key Talent and the realization of the enterprise's goal is much stronger compared with the ordinary employees. In the process of realizing enterprise strategic target, the necessary resources of realizing strategic objectives should first be defined, especially the human resources situation of the enterprise. The strength of enterprise human resources, which performs inimitability and market scarcity, affects the realization of strategic target. These features are exactly the attributes of Key Talent, so it is an important task present before the enterprise that how to identify Key Talent who is matching the vision, mission and goals of an enterprise through the scientific methods.

\section{2) Developing purpose.}

The identification of Key Talent is in favor of developing personnel. The continuous development to personnel is necessary for an enterprise if it wants to obtain competitive edge through HRM. In the identification process of Key Talent, the evaluation system and standards should be established, in which identification tools of Key Talent needs to be developed and measurement tools have to be implemented to find the gap between employees. Personnel training system should be constructed according to the standards, through which more Key Talents will be trained developed, which will increase the maximu m quantity of Key Talent.

\section{3) Administrative purpose.}

The identification of Key Talent is in favor of admin istrating personnel. Run-off of Key Talent will bring great loss to the enterprises because of the particularity of Key Talent, while the cost of introduction and training is relatively higher. Therefore, the enterprise needs to ensure which talents belong to Key Talent through the identification system of Key Talent, and then establish long-acting incentive mechanism accordingly. For example, to administrate Key Talent Scientifically adopting reasonable competitive Compensation System and providing better space to realize self-worth.

\section{IDENTIFYING KEY TALENT BASED ON POST EVALUAT ION AND COMPETENCY}

Zhang Taojing considers that the first thing to identify Key Talent is to find out key posts of the enterprise, and the next thing is to analyze the abilities and skills that the employee of a key post should possess. The standards of distinctiveness performance assessment are applied for the evaluation. Carrying out scarcity assessment after the sequencing of evaluation results and the selection of top $20 \%$ of outstanding achievement which can ensure the core staff group [7].

This paper argues that the identification of Key Talent should consider not only the human factors, but also think the post factors. The reasonable allocation of human resources is the matching problem of people and post, which will be realized with the premise of comprehensive and thorough understand to the key elements of human and post [8].

The talents at high-valued post may not be Key Talent and the post value that talents with higher able quality locate may not be high. Only those talents with higher able quality, who can create high performance, at high-valued post are Key Talent. The theory of Key Talent identification based on post evaluation competence makes up the shortcomings of the above situation. Therefore, the enterprise should identify Key Talent from post evaluation and competency, find out the influence factors and competence factors of the post value and use these factors to evaluate talents comprehensively, which will help the enterprise to discover its Key Talent.

\section{A. Identifying key talent based on post evaluation}

\section{1) Post evaluation.}

Post evaluation is to compare the various posts formally and systematically in order to ensure the process of relative value of posts. It measures the value of the post, but not the value of the incumbent on the post. The purpose to carry out 
the post evaluation is to ensure the levels of various posts according to the relative value that each post to the enterprise [9]. Post evaluation is to apply a certain methods to extract post value evaluation factors, ensure the important degree of each element and construct post value evaluation system based on post analysis.

\section{2) How to identify Key Talent applying post evaluation.}

Post evaluation is an essential condition to identify Key Talent. This paper argues that only those employees at high value posts have the possibility to become Key Talent. Therefore, the Key Talent identification system is established from the perspective, and the detailed steps are as follows.

\section{Step 1: Combing post system.}

Dividing the post sequence according to enterprise developmental strategy and putting those posts with similar properties and qualifications in as one category. The post sequence generally show as supervisory sequence, operated sequence, skilled worker sequence, operated worker sequence, and etc. Dividing post levels rationally and setting or adjusting posts according to organization scale, management range and post sequence.

\section{Step2: Post analysis .}

Making post description and defining qualifications according to post sequence which is to analyze the job content, responsibilities, job contact as well as the knowledge, ability, skills, physical condition and work environment that post personnel should possess through interview, observation and questionnaire and then form the job specification.

\section{Step 3: Extracting post evaluation elements .}

Post value evaluation factors can be extracted through two approaches.

First, apply general tools of post evaluation. MECER international post evaluation method is a unified standard of post evaluation designed by European scholars to coordinate with the European integration process, which is modified and perfected by MECER Management Consulting Company. It consists four factors: influence, communication, innovation and knowledge, which can be subdivided into effect, supervision, responsibility scope, communication skills and qualifications, difficulty of solving the problem as well as work features. Hewitt factor analys is contains the factors of knowledge and skills, influential responsibility, problem solution, decision-making, freedom of movement, communication skills as well as working environ ment. Z.M.C seven-factor analys is is a kind of evaluation tool designed by Zuojiaco Management Consulting Firm (Z.M.C) according to the characteristics of Chinese companies, whose factors mainly contain ability, influence, working independence, mistake consequences, communication skills, work control and thinking require ments [10]. When using the general tools, the evaluating posts can be graded according to the levels of each factor and the total weighting grades of each factor are the score of post evaluation. The general tools have been practiced and repeatedly proved, so they possess the advantages of higher reliability and validity as well as higher accuracy and scientificity, but is lack of pertinence comparing with individualized tools.

Second, apply individualized tools of post evaluation which needs to be developed according to the actual situation of the enterprise. Collect post information through the interview and questionnaire of expert group, form post specification and extract post evaluation factors. Individualized tools are the post evaluation factor system through repeatedly discuss by researchers, so the reliability and validity remain to be examined. Which tool can be used needs to analyze according to the specific circumstance. Because there are many differences between enterprises, this paper is in favor of using individualized tools to carry out post evaluation. Individualized tools need to be combined with the actual situation of the enterprise, whose core content is to extract each post value influence factors accurately.

Step 4: Ensuring weights and grades of each element.

Each factor has different importance in the evaluation process, so the weights of each element should be ensured by a certain methods. Subjective Weighting (invite relevant experts to give the weights of each factor and make the average of the weights as the final weight of each factor) has a stronger subjectivity. Analytic Hierarchy Process (invite relevant experts to make multiple comparisons, form judgment matrix, solve out the maximum characteristic root and then make consistency check) which combines qualitative and quantitative method, is a main method to design weight.

Step 5: Implementing evaluation and identification of highvalued post.

Organize experts to grade each factor according to the definition of post evaluation factor levels and weights and calculate the weighting grades. Order the post value grades and ensure high-value post. The top $20 \%$ of the posts can be confirmed as Key Talent based on Pareto's Law. Before implementation evaluation, expert group should be selected carefully, following the principle that evaluation subject and evaluation object have the most recent distant. This is because that they are more familiar with the posts which can make the evaluation result more accurate.

"Fig.1" shows the above detailed steps. 


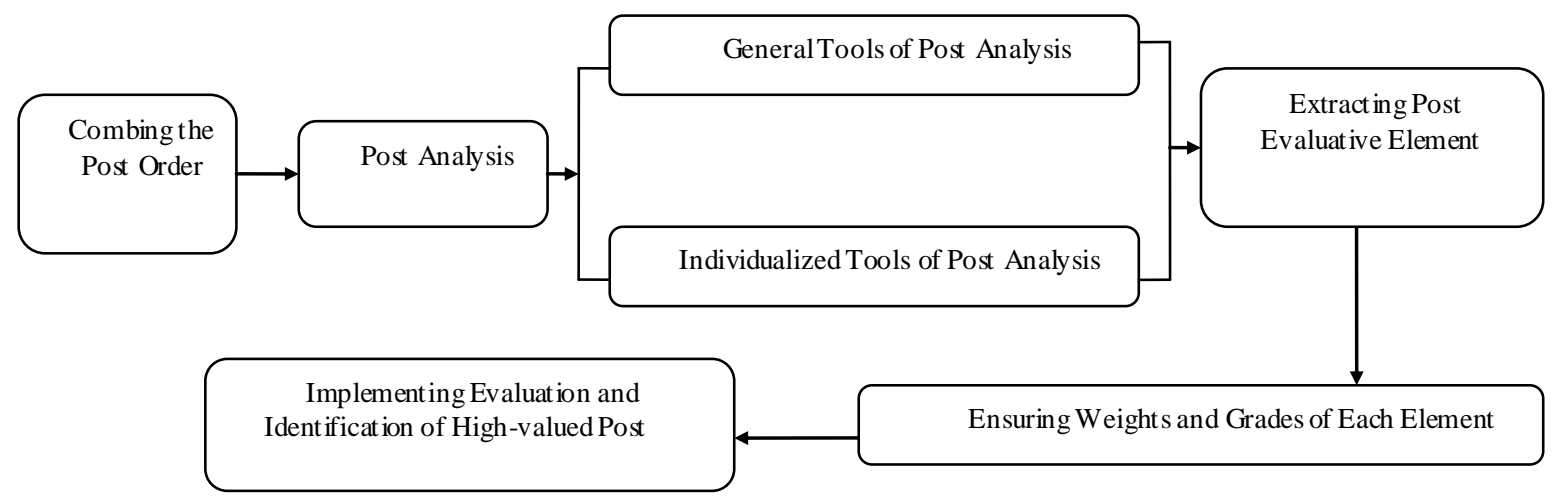

Fig. 1. The flow of identifying key talent by post evaluation

\section{B. Analyzing and identifying key talent based on competency}

\section{1) Competency}

Competency refers to deep personal characteristics which can distinguish the excellent and ordinary personnel in a work, which can be any individual characteristics that can be measured or counted reliably and distinguish outstanding with general performance, such as motive, characteristics, selfimage, attitudes and values, cognitive or behavioral skills [11]. The Competency Model refers to the total of competence factors that have to possess in order to complete a particular task role. The Iceberg Model, which is put forward by Spencer through study and application, is one theoretical basis of competency model. This model divides competency into explicit competency and implicit competency. Explicit competency, which is visible, includes knowledge and skills; while implicit competency, which is invisible, includes characteristics, motivation and self concept. The theory considers that implicit competency is the fundamental condition of explicit competency, and explicit competency is the external performance of implicit competency. Implicit competency, which plays a part in the actual performance through explicit competence, is the real factor determining the individual performance [12].

\section{2) How to indentify Key Talent applying competency}

The size of competency is another necessary condition to identify Key Talent. The performance of Key Talent plays an important role on the realization of enterprise strategic target, so competency quality factors and Key Talent identification system are studied from the perspective of enterprise strategy requirement. The detailed steps are as follows.

\section{Step 1: Extracting competency elements}

To apply competency theory to assess Key Talents, competency evaluation factors shall be determined based on the strategy. This paper puts forward using strategic performance management tools of Key Performance Indicators (KPI), Competitive Benchmarking Management and Behavior Event Interview (BEI) to determine the competency factors.

Key Performance Indicators (KPI) refers to the key indicators measuring the implementation effect of enterprise strategy [13], which is the bridge connecting personal performance and strategic goals. The extraction of key performance indicators needs to determine the successful key factors based on the strategy of enterprise first, and then decomposes successful factors in each layer into branched key performance indicators. Branched key performance indicators will then be decomposed into individual key performance indicators, which can deduce that what kind of quality and competence are needed to complete individual work, that is to say competency factors will be obtained. This method is strategic directed, which can ensure that employees' behavior keep consistent with enterprise development direction.

Competitive Benchmarking Management is a kind of benchmarking management taking competitive object as the basic standard, whose goal is to compare the performance and practice with the enterprises in the same market on product, service as well as working process and face competitors directly [14]. It is the process to learn from the excellent enterprises in or outside the industry and to imitate as well as innovate. Competitive Benchmarking Management is to use domestic and foreign experience of enterprises in the same industry for reference, to analy ze and study the imp licit quality possessed by excellent staff, and finally to form the staff competency factors of its own enterprise.

Behavioral Event Interview (BEI) is to make comparative study on the behavior characteristics of outstanding and ordinary staff in completing work mission through the deep interview of them, extract the knowledge, skills and deep individual characteristics that staff with excellent performance possess but ordinary staff do not have, thus extract co mpetency factors [15].

Quality and quantity should be paid attention when using above methods to extract competency factors which means that the extracted factors should be accurate and connected with the strategy, and it should also possess higher reliability and validity. The quantity should be appropriate because too-much factors will not have emphasis, too-few factors will be unilateral. Scholars also use statistical methods to ensure the competency factors, such as exploratory factor analysis and confirmatory factor analysis.

Step 2: Ensuring weights and grades of each element.

This step is the same as above post evaluation. 
Step 3: Constructing competency model and implementing evaluation and identification of Key Talent.

Constructing competency model of each post according to competency factors, organize expert group to evaluate and grade the staff, calculate the weighted scores of each personnel at various levels, and then determine the personnel with higher able quality. For the companies with large scale, the evaluating implementation is difficult, so they can operate with following steps: ensuring the post orders and levels according to post evaluation results, evaluate and select preliminarily in those candidates, and use competency model to evaluate the quality proficiency of personnel. The number of candidates can be ensured according to the number of high-value posts in a proportion.

Fig. 2 shows the above detailed steps.

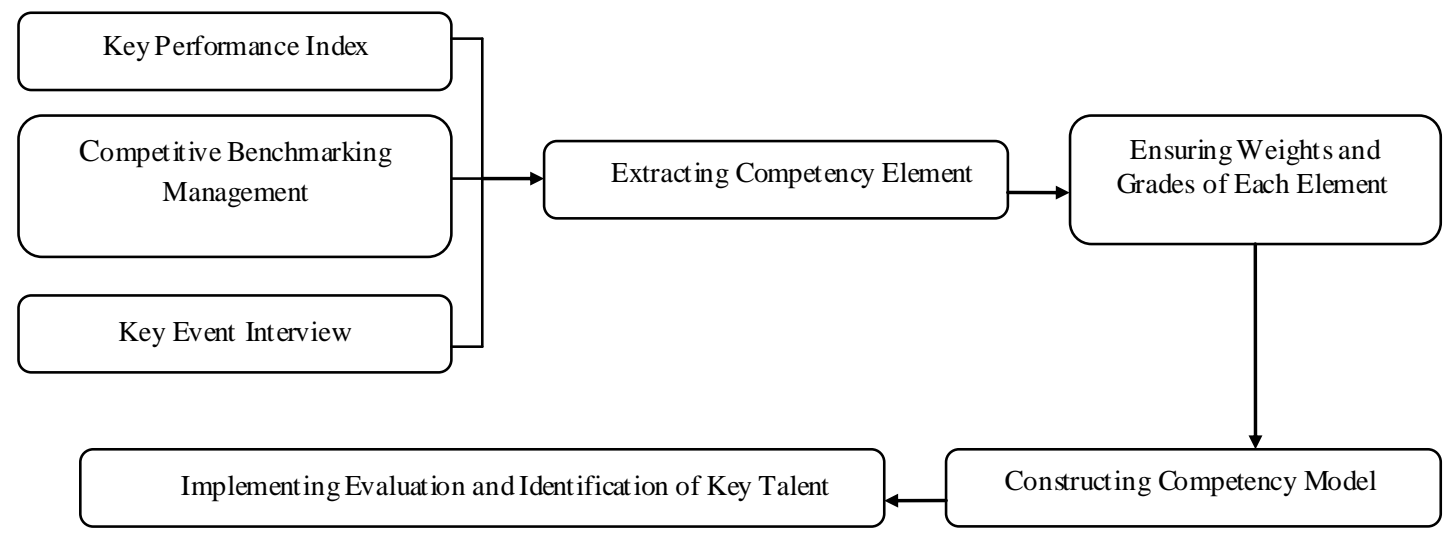

Fig. 2. The flow of identifying key talent by competency

\section{CONCLUSION}

This paper states from the main steps of the Key Talent identification from two dimensions which are traditional post evaluation and modern competency theory. Post evaluation is to evaluate the work content, duty and qualifications based on the work analysis, in which the evaluation of qualifications only contains the explicit competency of employees' knowledge and skills without evaluating the implicit competency. The introduction of competency theory to identify Key Talent in this paper actually makes up the shortcomings of the Key Talent identification through post evaluation. The performance of employees has advantages and disadvantages, and enterprise will pay more attention to those staff possessed which kind of personal characteristic will create higher performance.

\section{REFERENCES}

[1] YangXuguo,"Consideration of Organization Core Competence(Periodical style)," Enterprise Management, no.9,pp.9496,Sep.2005.

[2] Hu Junchen, Zheng Shaolian, Human Resource Develop-ment and Management (Book style). Shanghai: Fudan Uni-versity Press, 2001,pp. 323.

[3] Wan Xi, Yong Qidong,"Method Study on Information Industry Key Talent Performance Evaluation(Periodical style),"Science and Technology Management Research, no.2,pp. 64-66, Jan.2008.

[4] Leigh Branham,Retaining Key Employees (Book style). Beijing: China Labor Social Security Press, 2004.

[5] Dess.G.G,Shaw J.D.Voluntary Turnover, "Social Capital and Organizational Performance(Periodical style)," Academy of Management Review,no.26,pp. 446-456, 2001.
[6] Zhang Chengfen, "Analysis of the reasons for the core brain drain in high-tech enterprises(Periodical style)," Journal of Xi'an University of Post and Telecommunications,no.11,pp. 140-143,Nov. 2009.

[7] Zhang Taojing, "Study on Influencing Factors and Retention Strategy of Key Talent in High and New Tech Enterprises(Thesis style)," Hangzhou, Zhejiang University of Technology, 2008.

[8] Guo Qingsong, Shen Lin, "Post Analysis and Human R-esource Evaluation-T wo footstones of Human Resource Management(Periodical style)," Human Resource Develop-ment of China, no.5,pp.43-46, May.2002.

[9] Chen Lifen, Wang Weidong, "Managerial Job Evaluatio-n Based on Point-factor Method and IAHP in Enterprises(P-eriodical style)," Soft Science,no.4,pp.100-105,Apr. 2011.

[10] Qin Yangyong, Seven-step Approach of Payment Desi-gn (Book style).Xiamen: Lujiang Publishing House, 2008, pp.51-69.

[11] Huang Xunjing, Long Jing, " Innovation of Human R-esources Management System Based on Competency(Periodi-cal style),"Chinese Public Administration, no.4,pp.73-75, A-pr.2011.

[12] He Jianwen, " Empirical Study on the Factors of Innovative Talent Competency(Periodical style)," Science and Technology Management Research, no.2,pp.145-150,Feb. .2011.

[13] Fang Zhenbang,Strategic Performance Management (Book style).Beijing: China Renmin University Press, 2007,pp. 66.

[14] Wu Chunbo, Yu Qiang, "Study on Corporate Performance Improvement Based on Benchmarking Management(Periodical style),'Theory Monthly, no.9,pp. 159-162,Sep. 2009.

[15] Zhang Jun, "How to Evaluate and Develop employee's Post Competence(Periodical style)," Human Resource Development of China, no.5,pp. 44-46, May.2009. 